\title{
Soot CFD simulation of a real aero engine combustor
}

\author{
Florian Eigentler* and Peter Gerlinger ${ }^{\dagger}$ \\ Institute of Combustion Technology, German Aerospace Center (DLR), Stuttgart, 70569, Germany \\ Ruud Eggels \\ Rolls-Royce Deutschland Ltd \& Co KG, Brandenburg, 15827, Germany
}

\begin{abstract}
Soot evolution for a complex fuel is investigated with computational fluid dynamics (CFD). The soot model is evaluated using a Rolls-Royce BR700 annular combustor, based on the Rich-burn/Quick-quench/Lean-burn (RQL) concept. CFD computations are performed at take-off, climb, approach and idle operating conditions. Soot results are examined and compared with published engine data. The implemented kinetic model includes a detailed gas phase, a sectional approach for soot precursors, the polycyclic aromatic hydrocarbons (PAHs), and a two-equation model for soot particles. The models for PAHs and soot cover relevant growth, collision, agglomeration, and oxidation processes, and at the same time represent a good trade-off between accuracy and computational effort. In the steady-state Reynolds-averaged Navier-Stokes (RANS) simulations, finite-rate chemistry (FRC) is utilized for the calculation of chemical source terms. Turbulence is modeled with a standard $k-\epsilon$ approach, and influence on combustion is captured following an assumed probability density function (APDF) technique. A Lagrangian framework is further applied to describe the injection and evaporation of the liquid jet fuel surrogate. The objective of this work is the reproduction of experimentally identified trends, and to gain insight into the soot formation and oxidation of a real aero engine combustion chamber. The calculated Smoke number (SN) and Emission index (EI) at the combustor exit are used as comparative quantities. Good agreement between measurement and simulation is achieved.
\end{abstract}

\section{Introduction}

Unwanted by-products of combustion, such as soot, have negative impacts on climate, health, environment, and combustor wall heat load. ${ }^{1-5}$ In conjunction with the increasingly stringent legal regulations a further development of existing combustion technologies is required. ${ }^{6}$ Numerical CFD simulations with validated soot models can support this process and may reduce development costs. ${ }^{7}$ However, the simulation of a real aero engine poses a challenge to numerical combustion simulation. ${ }^{8}$ This includes, in addition to high pressures and temperature, a high degree of turbulence, the liquid injection of the kerosene fuel, the wall film cooling, and the varying local air-fuel ratios, to name only a few of the many complex processes.

To determine the chemical conversion in these simulations, flamelet approaches are frequently applied in literature. ${ }^{9-11}$ Due to its low computational effort, this approach has also already been used in largeeddy simulation (LES) of aero engines. ${ }^{10}$ However, the applicability of this method is not given in general, and therefore approaches based on detailed chemistry are also frequently implemented, ${ }^{12-14}$ also to evaluate the applicability and uncertainty of flamelet models. The considerably higher computational cost is offset by element and mass conservation, as well as the inherently and consistently coupled gas phase, PAH and soot chemistry. Modeling soot particles in these simulations presents a particular challenge. Most of the developed and investigated soot models are limited to small hydrocarbon fuels and cannot be directly applied. ${ }^{15-17}$ Some models have already been extended to complex fuels. ${ }^{18-20}$ However, most of them are applied to academic test cases and are not suited for complex CFD simulations, due to their large number

*PhD Student, German Aerospace Center (DLR), Stuttgart, 70569, Germany

${ }^{\dagger}$ Professor, German Aerospace Center (DLR), Stuttgart, 70569, Germany

$\ddagger$ Development Engineer, Rolls-Royce Deutschland Ltd \& Co KG, Brandenburg, 15827, Germany 


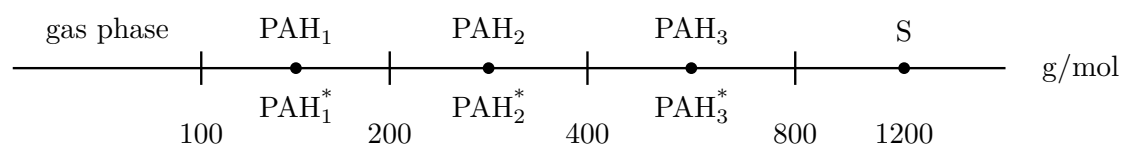

Figure 1. Discretization of the mass spectrum for gas phase, PAHs and soot model. $\mathrm{PAH}_{\mathrm{i}}^{*}$ denotes a radical belonging to the respective PAH section.

of species and reactions. ${ }^{21}$ Reduction strategies were defined to generate mechanisms tailored to a specific operating condition at the price of losing its general applicability. ${ }^{22-26}$ Thus, in combination with FRC a soot model is required which, on the one hand, is large enough to be used without test case dependent modifications and, on the other hand, requires as little computational effort as possible. Such a model has been developed and investigated in a previous work and is here applied to a more complex test case. ${ }^{27,28}$

The Rolls-Royce BR700 annular combustor is numerically examined in this work. ${ }^{29,30}$ In this RQL combustion chamber liquid fuel (Jet A-1) is injected into the rich-burn zone by an air-blast injector. For reasons of flame stabilization, spray droplet breakup and a better mixing, the injector consists of three air swirl generators. The fuel is injected using a liquid pre-filmer in between the inner and middle air swirler. The rich conditions in the primary zone lower the temperature levels and thus keep the $\mathrm{NO}_{\mathrm{x}}$ emissions low, but also increase the formation of soot. Further downstream, in the quick-quench zone, a rapid mixing with additional oxygen is achieved by primary and secondary dilution air feeds. Thereby, the transition to the lean-burn zone is initiated in which the oxidation of soot is favored at sufficiently high temperatures. Emissions can be kept at a minimum if temperature levels are well balanced between the limits for soot oxidation and thermal $\mathrm{NO}_{\mathrm{x}}$ formation. Four operating points (thrust levels), relevant for the International Civil Aviation Organization (ICAO) engine certification, are investigated in this work. These load cases involve take-off (100\%), climb (85\%), approach (30\%) and idle (7\%).

\section{Methodology}

The following steady-state RANS simulations are performed with the unstructured finite volume solver Predictive-System for Real Engine Combustors - Unstructured (PRECISE-UNS) developed by Rolls-Royce. ${ }^{31}$ This solver is based on a pressure correction method, initially developed for incompressible, but next extended to compressible, flows. The simulation framework provides several combustion and turbulence models. In this work, a standard $k-\epsilon$ turbulence model is chosen. ${ }^{32}$ Moreover, this solver provides a Lagrangian framework for spray particle tracking. Therein, a steady-state evaporation model and stochastic methods for turbulent fluctuations are implemented. ${ }^{33,34}$

The thermo-chemical state in the combustor is defined by transport equations of enthalpy and species mass fractions. Analogously to enthalpy and gaseous molecules, an Eulerian approach is chosen for soot particles. While differential diffusion is considered for the gas phase species and PAHs, soot is diffusively transported by thermophoresis only. ${ }^{35}$ Species source terms by chemical conversion are calculated by a point-implicit FRC solver, developed at the German Aerospace Center (DLR). Therein, turbulence-chemistry interaction is addressed via an APDF approach. ${ }^{13}$ For this purpose, each reaction rate of the kinetic scheme is averaged over the entire temperature fluctuation range assuming a Gaussian distribution, supplemented by up to two Dirac pulses if required. This calculation is performed in a pre-processing step and the reaction rates, later used in the simulation, are stored in tables. The radiation of certain species is considered by assuming an optically thin medium, whereby emitted radiation is not reabsorbed. ${ }^{36}$ In view of the dominant pressure, especially for the $100 \%$ load case, a partial violation of this assumption is to be expected. Nevertheless, this method is computationally efficient and may be preferable to a simulation without radiation influence. $\mathrm{CO}_{2}$, $\mathrm{H}_{2} \mathrm{O}$ and soot are considered as important radiative species. ${ }^{37}$

\section{A. Chemical and soot modeling}

The kinetic scheme of the soot model is composed of the sub models for gas phase, PAHs and soot. ${ }^{28} \mathrm{~A}$ schematic representation of these sub models against their molar mass is shown in Fig. 1. The gas phase is based on a skeletal mechanism developed for small hydrocarbons, which has been extended to complex fuels and blends. ${ }^{38,39}$ The scheme covers species up to a molar mass of $100 \mathrm{~g} \mathrm{~mol}^{-1}$, and thus also aromatic one- 
ring structures, e.g., benzene or toluene. The mechanism has been optimized in terms of numerical stability and includes a total number of 112 species and 848 reactions. Subsequently to gas phase species, the PAHs are modeled using a sectional approach. Three sections, logarithmically increasing in size, span over a mass range from 100 to $800 \mathrm{~g} \mathrm{~mol}^{-1}$. Each of these sections is supplemented by a PAH radical $\left(\mathrm{PAH}^{*}\right)$, to capture the reversibility of the hydrogen abstraction and carbon addition (HACA) mechanism. ${ }^{40}$ In addition to PAH growth from acetylene, the model also includes the processes of collision and oxidation. Moreover, the interaction between gas phase and first PAH and PAH radical section is defined by additional reactions. Thermodynamic and transport properties for the PAHs are taken from reference species.

In this work, soot particles are described as mono-disperse particles, and therefore transport equations for the soot mass fraction $\left(Y_{S}\right)$ and the soot particle number density $\left(N_{S}\right)$ have to be defined. Following Einstein's summation convention, the transport equations for $Y_{S}$ and $N_{S}$ read as follows

$$
\begin{gathered}
\frac{\partial}{\partial t}\left(\bar{\rho} \tilde{Y}_{S}\right)+\frac{\partial}{\partial x_{i}}\left(\bar{\rho} \tilde{u}_{i} \tilde{Y}_{S}\right)=\frac{\partial}{\partial x_{i}}\left(\frac{\mu_{t}}{S c_{t}} \frac{\partial \tilde{Y}_{S}}{\partial x_{i}}\right)+\frac{\partial}{\partial x_{i}}\left(C_{t h} \frac{\mu \tilde{Y}_{S}}{\bar{T}} \frac{\partial \bar{T}}{\partial x_{i}}\right)+\bar{\omega}_{Y_{S}}, \text { and } \\
\frac{\partial}{\partial t}\left(\bar{\rho} \tilde{N}_{S}\right)+\frac{\partial}{\partial x_{i}}\left(\bar{\rho} \tilde{u}_{i} \tilde{N}_{S}\right)=\frac{\partial}{\partial x_{i}}\left(\frac{\mu_{t}}{S c_{t}} \frac{\partial \tilde{N}_{S}}{\partial x_{i}}\right)+\frac{\partial}{\partial x_{i}}\left(C_{t h} \frac{\mu \tilde{N}_{S}}{\bar{T}} \frac{\partial \bar{T}}{\partial x_{i}}\right)+\bar{\omega}_{N_{S}} .
\end{gathered}
$$

In the equations $\rho$ denotes the density, $u_{i}$ the i-th velocity component, $\mu_{t}$ the turbulent viscosity, $S c_{t}$ the turbulent Schmidt number, $C_{t h}$ the thermophoretic coefficient, $\mu$ the laminar viscosity, $T$ the temperature, and $\omega$ the chemical source term. For $Y_{S}$ and $N_{S}$ the thermophoretic coefficient $C_{t h}$ is set to 0.55 and the turbulent Schmidt number $S c_{t}$ to 0.7. The only difference between Eqs. (1) and (2) is in the calculation of the source term $\bar{\omega}$. While $\bar{\omega}_{Y_{S}}$ is calculated as a function of molar mass, stoichiometric coefficients, reaction rate and concentration, ${ }^{13,41} \bar{\omega}_{N_{S}}$ depends on the mixture's density in place of the molar mass. Consistent with incipient soot particles, ${ }^{42}$ the molar mass of soot is set to $1.2 \mathrm{~kg} / \mathrm{mol}$. A predefined $\mathrm{H} / \mathrm{C}$ ratio of 0.5 is assumed for soot particles, leading to a molar composition of $96 \mathrm{C}$ atoms and $48 \mathrm{H}$ atoms. The soot density $\rho_{S}$ is defined to be $1800 \mathrm{~kg} \mathrm{~m}^{-3} .{ }^{43}$ The average diameter and the surface per unit volume of these soot particles is given by

$$
\begin{aligned}
d_{S} & =\sqrt[3]{6 \rho Y_{S} /\left(\pi \rho_{S} N_{A} N_{S}\right)}, \text { and } \\
A_{S} & =\sqrt[3]{36 \pi N_{A} N_{S} \rho^{2} Y_{S}^{2} / \rho_{S}^{2}},
\end{aligned}
$$

respectively. The model takes into account the processes of inception, collision with PAHs, agglomeration and oxidation. Soot inception takes place through collision reactions of the $\mathrm{PAHs}$ which include the $\mathrm{PAH}_{3}$ and the $\mathrm{PAH}_{3}^{*}$ section. Surface growth is modeled following the HACA mechanism. ${ }^{40}$ In the case of soot, a radical counterpart species is neglected to keep the computational effort as low as possible. However, the influence of a radical soot species is still taken into account by assuming a quasi steady-state which yields

$$
k_{S, \text { surface }}=\alpha k r_{\chi} \chi A_{S}
$$

for the reaction rate of surface processes. ${ }^{44}$ In this equation, $\alpha$ is a function of temperature, $k$ denotes the respective rate coefficient, $r_{\chi}$ the ratio of reactive to stable sites, and $\chi$ the density of stable $\mathrm{H} / \mathrm{C}$ sites $\left(2.32 \times 10^{-19} 1 / \mathrm{m}^{2}\right)$. To obtain an Arrhenius like form for this reaction rate, the $\alpha$ function is defined to be

$$
\alpha\left(T, c_{\alpha}, T_{\alpha}, n_{\alpha}\right)=c_{\alpha}\left(T_{\alpha} / T\right)^{n_{\alpha}} \exp \left(n_{\alpha}\left[1-T_{\alpha} / T\right]\right),
$$

with the coefficients $c_{\alpha}=1, T_{\alpha}=1800$ and $n_{\alpha}=40 .{ }^{45}$ The ratio of reactive to stable sites requires calibration. In an extensive validation of the model over many different shock tube experiments and well-studied laboratory flames, best results have been achieved with a value of $2.5 \times 10^{-3} \cdot{ }^{28}$ Since $N_{S}$ is determined at runtime but already is required in the definition of collision rate coefficients (see $d_{S}$ ), the approach of $\mathrm{Di}$ Domenico et al. ${ }^{46}$ is followed, in which the superposition of reactions is used to isolate $N_{S}$ from a reaction equation. Due to the mono-disperse soot size distribution, the efficiency of soot agglomeration is increased to 3 , compared to a sectional approach, ${ }^{28}$ which is also in agreement with previous works. ${ }^{46}$ Soot oxidation takes place through $\mathrm{O}_{2}$ and $\mathrm{OH}$, where the dominant path is represented by the latter one. While the kinetic theory of gases is used for the rate calculation of $\mathrm{OH}$ with an efficiency of 0.27 , the oxidation by $\mathrm{O}_{2}$ is implemented following the surface process approach given above. Rate coefficients are taken from Fenimore and Jones, ${ }^{47}$ and Appel et al., ${ }^{48}$ respectively. Moreover, a combination of three $\mathrm{OH}$ oxidation reactions, 


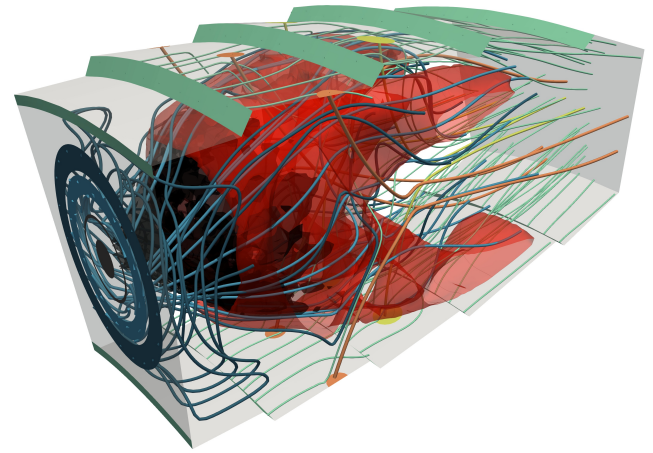

(a) Rendered combustion chamber

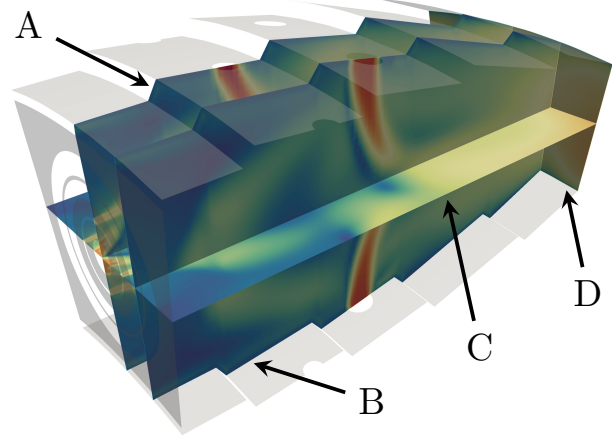

(b) Cut planes overview

Figure 2. Rendered simulation domain of the Rolls-Royce BR700 annular combustor (a) and overview of selected cut planes (b). Shown are streamlines from swirl generators (blue), primary (orange) and secondary (yellow) dilution air feeds, effusion wall cooling (green), and contours for significant spray source term (black) and high temperatures (red) in the figure on the left.

each superimposed with a different $\alpha$ function, is used to account for the decreasing oxidation efficiency towards lower temperatures. ${ }^{49}$ A least-square technique was utilized to determine these functions to be $\alpha_{1}=\alpha(T, 0.85,1736.86,70), \alpha_{2}=\alpha(T, 0.45,2180.37,70)$ and $\alpha_{3}=\alpha(T, 0.97,2978.08,16.87)$.

The models for gas phase, PAHs and soot are further supplemented with polyynes and related reactions paths. These species may represent a further PAH and soot growth path, especially at higher temperatures. ${ }^{50-52}$ A more detailed description of the implemented model can be found in the previous validation work. $^{28}$

\section{Numerical setup}

The annular combustion chamber BR700 from Rolls-Royce is simulated using the soot model presented above. In this study the four operating points take-off, climb, approach and idle are investigated. Corresponding thrust levels and fuel mass flows are summarized in Table 1. As specified by the manufacturer, combustion chamber pressure and air inlet temperature are reduced with decreasing thrust level, while the air-fuel ratio is increased. To keep the computational effort as low as possible, only a $18^{\circ}$ segment with symmetry boundary conditions is considered in the simulations, as shown in Fig. 2a. The chosen section covers one injector and extends up to half the distance to the nearest adjacent injector. The resulting mesh comprises of roughly 200,000 volumes and, despite the application in an unstructured solver, consists of hexahedral and quadrilateral elements only. The computational effort is about 70,000 CPUh per operating point for the chosen grid, gas phase kinetics, and soot model. Since kerosene consists of many different components, and may vary strongly, the fuel is described by a surrogate consisting of only a few important species. Since, the choice of a fuel surrogate may introduce a large uncertainty to the simulation, a surrogate is chosen, which has already been applied in previous works for kerosene where it achieved good results. ${ }^{28}$ Therein, a blend of $65 \mathrm{vol}-\%$ n-decane, $23 \mathrm{vol}-\%$ iso-octane and $12 \mathrm{vol}-\%$ toluene is chosen as a replacement for real kerosene (Jet A-1).

Table 1. Fuel mass flow boundary condition for the simulations. Given are thrust level (\%) and fuel mass flow per segment $\left(\mathrm{g} \mathrm{s}^{-1}\right)$ for the respective operating point. ${ }^{53}$

\begin{tabular}{rcccc}
\hline & take-off & climb & approach & idle \\
\hline thrust level & 100 & 85 & 30 & 7 \\
fuel mass flow & 35.71 & 29.74 & 10.72 & 4.46 \\
\hline
\end{tabular}




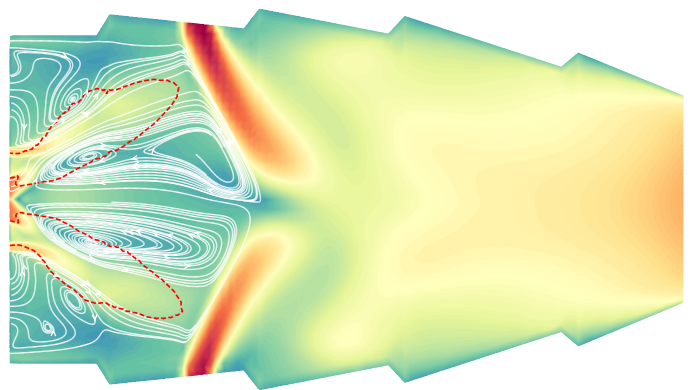

(a) Cut plane A

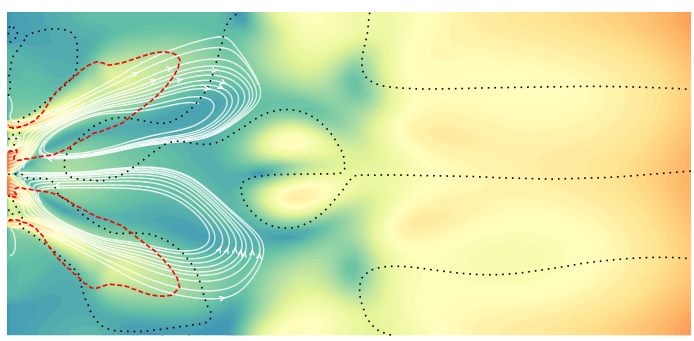

(c) Cut plane C

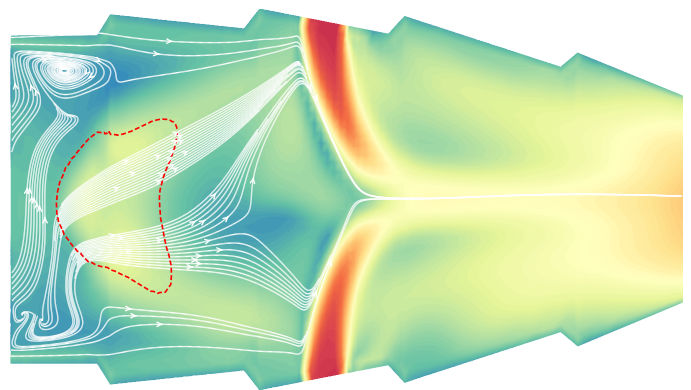

(b) Cut plane B

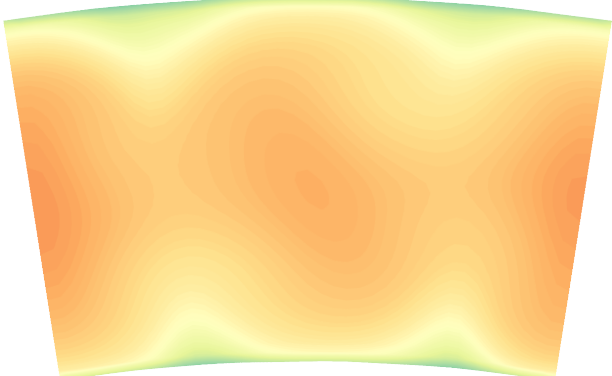

(d) Cut plane D

\begin{tabular}{cccccc}
\hline & 1 & 1 & 1 & 1 & \\
0.0 & 0.2 & 0.4 & 0.6 & 0.8 & 1.0 \\
& & & norm. & velocity & magnitude $(-)$
\end{tabular}

Figure 3. Calculated normalized flow field contour plots in different cross-sections (a-d) of the combustion chamber for the take-off operating point (100\%). Superimposed are streamlines starting from the combustor inlet (white), and iso-lines of fuel mass fraction $Y_{f}=1 \%$ (red dashed) and negative velocity perpendicular to the section plane (black dotted).

\section{Results and discussion}

A schematic representation of the simulation domain is visualized in Fig. 2a. The geometry is superimposed with streamlines from the swirl generators (blue), primary (orange) and secondary (yellow) dilution air feeds, and effusion wall cooling (green). Corresponding boundary condition surfaces are highlighted in equivalent colors. Moreover, two contour surfaces are shown for significant spray source terms (black) and high temperatures (red). An overview of chosen cross-sections is illustrated in Fig. 2b. The selected cut planes show only a specific part of the complex flow field, but nevertheless, most important processes can be observed.

The magnitude of the velocity field is shown for the $100 \%$ operating point in different cross-sections in Fig. 3. The visible areas of high velocity include the injector streams, as well as the primary and secondary dilution air feeds. As can be seen by the streamlines in Figs. 3a and 3b, the dilution air causes the quenching of the fuel-rich zone. The swirlers favor the flame stabilization and lead to the formation of two main recirculation zones (inner and outer) in the fuel-rich zone. The area of fuel mass fraction $Y_{f}=1 \%$ (red dashdotted) is located between these recirculation zones, whereby spray droplet breakup, evaporation and mixing is favored. Figure 3c shows that the upper and lower central primary air do not coincide coaxially but push each other apart. This is also apparent from the superimposed iso-lines of negative velocity perpendicular to the section plane, which extend asymmetrically across the cut plane. 

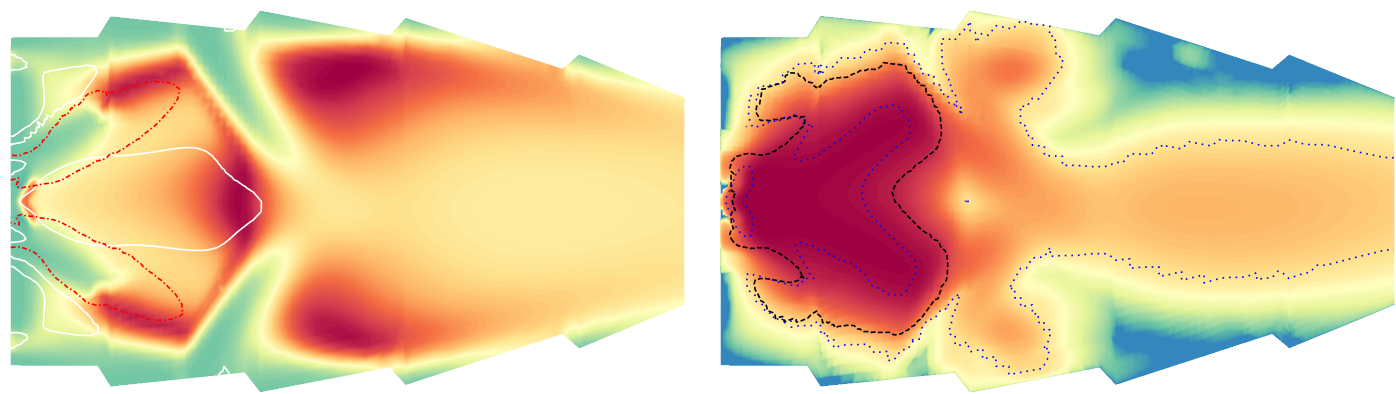

(a) take-off $(100 \%)$
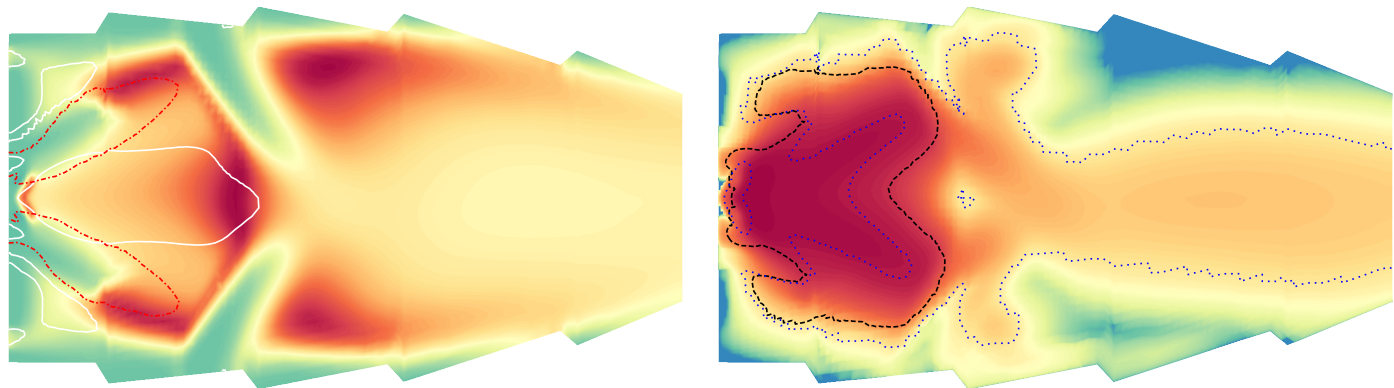

(b) $\operatorname{climb}(85 \%)$
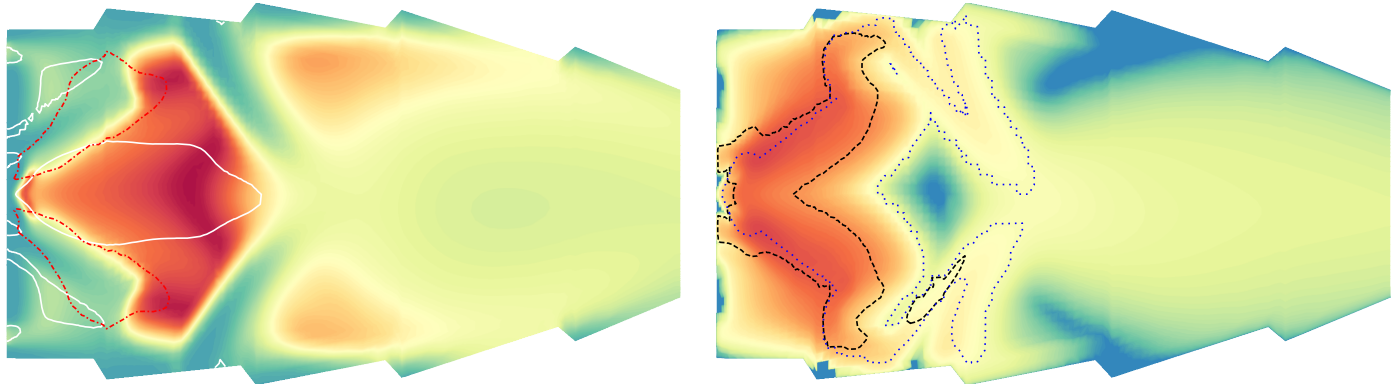

(c) approach $(30 \%)$
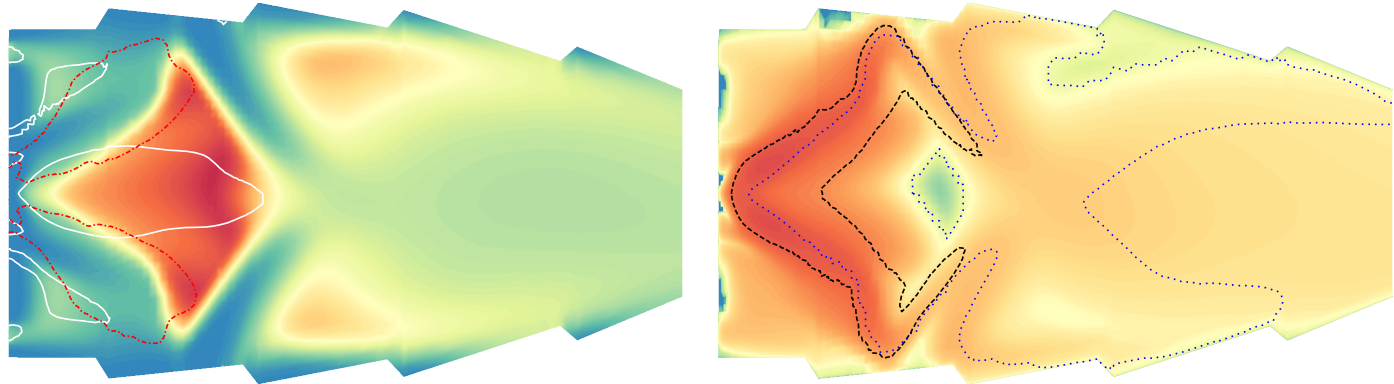

(d) idle $(7 \%)$
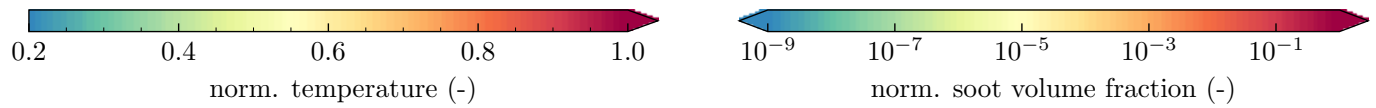

Figure 4. Calculated normalized temperature (left) and soot volume fraction (right) contour plots in crosssection $\mathbf{A}$ of the combustion chamber, for the operating points take-off (a), climb (b), approach (c), and idle (d). Superimposed are iso-lines of fuel mass fraction (red dash-dotted), zero velocity (white solid), soot formation (black dashed) and oxidation (blue dotted). 
In Fig. 4 the normalized temperature and soot volume fraction contour plots are given for all examined thrust levels. The normalization is achieved with the maximum values taken from the take-off operating point in Fig. 4a. The contour plots of the temperature are superimposed with iso-lines of zero velocity (white solid) and fuel mass fraction (red dash-dotted). The plots for soot volume fraction are superimposed with regions of soot formation (black dashed) and soot oxidation (blue dotted).

Comparing the different operating points for the normalized temperature plots in Fig. 4 shows that the temperature fields in the fuel-rich zone change significantly between the $85 \%$ and the $30 \%$ operating point. The regions of maximum temperature, between inner and outer recirculation zone, shrink with decreasing thrust level and disappear completely in the $7 \%$ case. In addition, areas of maximum temperature move further upstream with decreasing thrust level. This observed trend does not continue with transition from the $30 \%$ to the $7 \%$ load case. In the latter one the temperature in the inner recirculation zone decreases significantly. A similar behavior can be observed for the fuel mass fraction $Y_{f}=1 \%$ (red dash-dotted) in Fig. 4. With a decreasing thrust level, down to $30 \%$, the spray cone angle expands, and then collapses slightly in the $7 \%$ case again. The iso-lines for zero velocity $v=0.0 \mathrm{~m} \mathrm{~s}^{-1}$ (white solid), which also indicate areas of recirculation, are almost identical across the operating points. As well the lean zones in the rear part of the combustor show apart from the dropping temperatures very similar distributions. The areas of high temperatures wind around the primary and secondary dilution air feeds.

Also deviations occur between the operating points for the normalized soot volume fractions plotted in Fig. 4. Most soot volume fraction is predicted for the $100 \%$ load case in the fuel rich-zone. A very similar distribution is observed for a thrust level of $85 \%$. Considerably less soot with a distinctly different distribution, is obtained for the $30 \%$ and the $7 \%$ operating points. Differences have also already been found in the temperature plots. The least soot concentration is predicted for the $30 \%$ case. Similar levels are reached in the $7 \%$ case in fuel-rich zone, however, the entire combustion chamber is noticeably more covered with soot. This is also visible by the source term of soot formation (black dashed). While these areas are limited to the fuel-rich zone for the $100 \%, 85 \%$ and $30 \%$ case, soot formation almost reaches the lean zone in the $7 \%$ case. Concerning soot oxidation, additional source terms are visualized with blue dotted iso-lines. As expected, oxidation extends over the entire combustor in the $85 \%$ and $100 \%$ operating point. The significantly less formed soot in the $30 \%$ case, leads to a completion of soot oxidation in the first half of the combustor. In the $7 \%$ load case, areas of significant soot oxidation extend further downstream into the lean zone of the combustion chamber, but do not compensate for the increased soot formation.

\section{A. Smoke number and Emission index}

Experimental measurements of combustion chambers in aero engines under real operating conditions are usually not publicly available. However, legal regulations require the publication of engine data for the certification. One of these published values is the Smoke number (SN), measured at the engine outlet. Conclusions about the combustion chamber can be drawn by considering the bypass air and turbine cooling. The calculation of the SN in the simulation is obtained with the integrated soot concentration at the combustion chamber exit as follows,

$$
C_{S}= \begin{cases}0.06949 S N^{1.234}, & \text { for } S N \leq 30 \\ 0.0297 S N^{2}-1.803 S N+31.94, & \text { for } S N>30 .\end{cases}
$$

In the equation, $C_{S}$ denotes the soot concentration with the unit $\mathrm{mg} \mathrm{m}^{-3}$. The experimental values are taken from the public ICAO database. ${ }^{53}$ The SN results for the investigated operating points are shown in Fig. 5a. Regarding the trends, simulation and experiment agree very well. The SN decreases, as the thrust level is reduced to $30 \%$. The measurement at $7 \%$ shows an increase of the SN, which is also predicted in the simulation. Concerning, the values, the best agreement is achieved for the $30 \%$ case. The $85 \%$ and the $100 \%$ thrust levels are slightly underestimated. The highest deviation is observed for the $7 \%$ operating point. Deviations are nearly within one order of magnitude.

Another parameter for comparison is the Emission index (EI), given in units soot per kilogram fuel. For the mass-based EI (mg/kg fuel) similar trends are achieved in comparison with the SN in Fig. 5b. Absolute deviations increase but are still within 1-2 orders of magnitude. Results for the number-based EI (\#/kg fuel) can be seen in Fig. 5c. While good agreement is achieved for the take-off and climb operating points, approach and idle particle numbers diverge by 1-2 orders of magnitude. Although the deviation in 


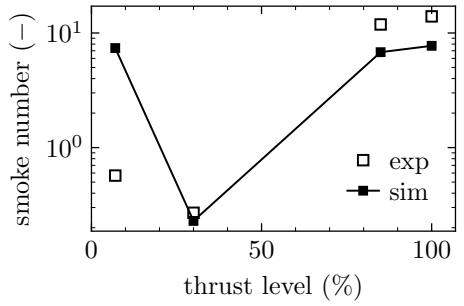

(a) Smoke number

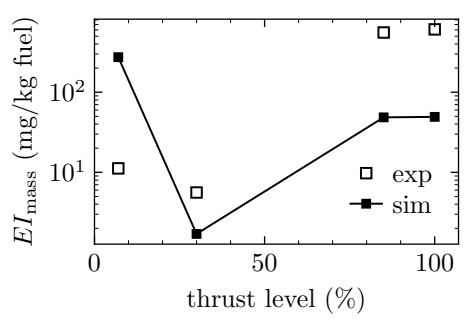

(b) Emission index (mass)

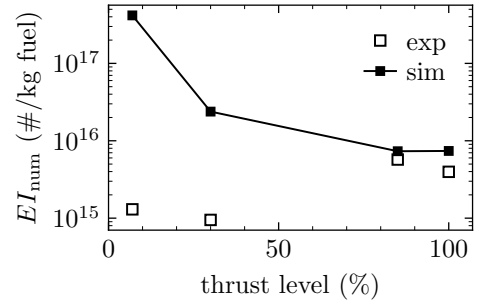

(c) Emission index (number)

Figure 5. Measured and calculated SN (a), particle mass (b) and particle number (c) based EI at the combustion chamber exit (cross-section D). Open symbols: experimental data; ${ }^{53}$ lines with filled symbols: simulation results.

the idle case may be attributed to the overpredicted particle mass, the soot model seems to reflect the trend only partially. Since soot is modeled as a mono-disperse spherical particle in the chosen two-equation model, particle agglomeration and aggregation may be underestimated, which in turn leads to an overprediction of particle number. Measured and predicted SN and EI values are summarized in Table 2.

Table 2. Measured (exp) and predicted (sim) emission values at the combustion chamber exit (cross-section D). Given are thrust level (\%), SN (-), particle mass based (mg/kg fuel), and particle number based (\#/kg fuel) EI for the respective operating point. ${ }^{.53}$

\begin{tabular}{rcccrrrl}
\hline & \multirow{2}{*}{ thrust level } & \multicolumn{2}{c}{ SN } & \multicolumn{2}{c}{ EI (mass) } & \multicolumn{2}{c}{ EI (number) } \\
& & exp & sim & exp & \multicolumn{1}{c}{ sim } & exp & sim \\
\hline take-off & 100 & 13.96 & 7.73 & 608.50 & 49.24 & $3.97 \times 10^{15}$ & $7.39 \times 10^{15}$ \\
climb & 85 & 11.87 & 6.80 & 556.50 & 48.55 & $5.72 \times 10^{15}$ & $7.33 \times 10^{15}$ \\
approach & 30 & 0.27 & 0.23 & 5.60 & 1.70 & $9.49 \times 10^{14}$ & $2.38 \times 10^{16}$ \\
idle & 7 & 0.57 & 7.39 & 11.20 & 273.80 & $1.30 \times 10^{15}$ & $4.17 \times 10^{17}$ \\
\hline
\end{tabular}

\section{Summary and conclusions}

In this work, an aero engine combustor has been investigated by steady-state RANS simulations. FRC with APDF turbulence-chemistry interaction is utilized to describe the chemical conversion of evaporated fuel, towards soot precursors and finally to soot particles. The kinetic scheme employed here, concludes a detailed gas phase mechanism, a sectional PAH model and an efficient two-equation soot model. Soot tendencies for the operating points take-off, climb, approach, and idle are compared to SN and EI measurements. The observed phenomena, as well as the results of the comparison to the experiments are:

The concept of a RQL combustion chamber is reproduced for all examined operating points. A highly swirled inflow causes the formation of recirculation regions in the fuel-rich zone of the combustor, especially important for reasons of flame stabilization. The areas of high temperature and highest soot volume fraction are quenched by the primary dilution air injection, which together with the secondary air introduces the lean zone, where the oxidation of soot takes place.

The experimentally identified SN trends with decreasing thrust are reproduced well by the model. The operating points of highest thrust (take-off and climb) are very similar. As observed in the experiments, the least soot concentration is obtained for the approach case in the simulation, too. Even the observed increase in soot emission for the idle operating point is reproduced by the model, but also shows the maximum deviation to the experiment. Predicted trends of the mass-based EI are similar to the SN. A diverging trend to the experiment is found for the particle number related EI in the approach and idle case, which is due to the overestimation of the particle mass in the idle case, but also to the soot model used.

Despite many uncertainties, e.g., in fuel composition, turbulence modeling and interaction with chemistry, but also in the experimental values, the model provides good results and clearly demonstrates its applicability, to be used in soot simulations for complex real combustors. The model identifies regions with strong soot 
formation and soot oxidation and reproduces mass-based emission trends very well. Further studies with a more complex soot model (sectional approach) may improve the prediction of particle number emission trends.

\section{References}

${ }^{1}$ Wulff, A. and Hourmouziadis, J., "Technology Review Of Aeroengine Pollutant Emissions," Aerosp. Sci. Technol., Vol. 1, 1997, pp. 557-572.

${ }^{2}$ Ammann, M., Kalberer, M., Jost, D., Tobler, L., Rössler, E., Piguet, D., Gäggeler, H., and Baltensperger, U., "Heterogeneous Production Of Nitrous Acid On Soot In Polluted Air Masses," Nature, Vol. 395, 1998, pp. 157-160.

${ }^{3}$ Travis, D. J., Carleton, A. M., and Lauritsen, R. G., "Contrails Reduce Daily Temperature Range," Nature, Vol. 418, No. 6898, Aug. 2002, pp. 601-601.

${ }^{4}$ Prüss-Ustün, A., Wolf, J., Corvalán, C., Bos, R., and Neira, M., Preventing Disease Through Healthy Environments: A Global Assessment Of The Burden Of Disease From Environmental Risks, World Health Organization, Geneva, Switzerland, 2016.

${ }^{5}$ Burkhardt, U., Bock, L., and Bier, A., "Mitigating The Contrail Cirrus Climate Impact By Reducing Aircraft Soot Number Emissions," npj Clim. Atmos. Sci., Vol. 1, No. 1, oct 2018.

${ }^{6} \mathrm{ICAO}$, Committee on Aviation Environmental Protection, Vol. 11, International Civil Aviation Organization (ICAO), Montreal, Canada, 2019.

${ }^{7}$ Konstantinos, G., "Future Aero Engine Designs: An Evolving Vision," Advances in Gas Turbine Technology, InTech, nov 2011, pp. 3-24.

${ }^{8}$ Fiorina, B., Vie, A., Franzelli, B., Darabiha, N., Massot, M., Dayma, G., Dagaut, P., Moureau, V., Vervisch, L., Berlemont, A., Sabelnikov, V., Riber, E., and Cuenot, B., "Modeling Challenges in Computing Aeronautical Combustion Chambers," AerospaceLab Journal, Vol. Issue 11, 2016, pp. 2107-6596.

${ }^{9}$ Fairweather, M., Jones, W., Ledin, H., and Lindstedt, R., "Predictions Of Soot Formation In Turbulent, Non-Premixed Propane Flames," Symp. (Int.) Comb., Vol. 24, No. 1, Jan. 1992, pp. 1067-1074.

${ }^{10}$ Mueller, M. E. and Pitsch, H., "LES Model For Sooting Turbulent Nonpremixed Flames," Combust. Flame, Vol. 159, No. 6, June 2012, pp. 2166-2180.

${ }^{11}$ Wick, A., Attili, A., Bisetti, F., and Pitsch, H., "Dns-Driven Analysis Of The Flamelet/Progress Variable Model Assumptions On Soot Inception, Growth, And Oxidation In turbulent flames," Combust. Flame, Vol. 214, April 2020, pp. 437-449.

${ }^{12}$ Zamuner, B. and Dupoirieux, F., "Numerical Simulation Of Soot Formation In A Turbulent Flame With A Monte-Carlo PDF Approach And Detailed Chemistry," Combust. Sci. Technol., Vol. 158, No. 1, Sept. 2000, pp. $407-438$.

${ }^{13}$ Gerlinger, P., Numerische Verbrennungssimulation, Springer-Verlag, 2004.

${ }^{14}$ Eberle, C., Gerlinger, P., and Aigner, M., "A Sectional PAH Model With Reversible PAH Chemistry For CFD Soot Simulations," Combust. Flame, Vol. 179, May 2017, pp. 63-73.

${ }^{15}$ Carbonell, D., Oliva, A., and Perez-Segarra, C., "Implementation Of Two-Equation Soot Flamelet Models For Laminar Diffusion Flames," Combust. Flame, Vol. 156, No. 3, March 2009, pp. 621-632.

${ }^{16}$ Eberle, C., Gerlinger, P., Geigle, K., and Aigner, M., "Numerical Investigation Of Transient Soot Evolution Processes In An Aero-Engine Model Combustor," Comb. Sci. Tech., Vol. 187, 2015, pp. 1841-1866.

${ }^{17}$ Saggese, C., Ferrario, S., Camacho, J., Cuoci, A., Frassoldati, A., Ranzi, E., Wang, H., and Faravelli, T., "Kinetic Modeling Of Particle Size Distribution Of Soot In A Premixed Burner-Stabilized Stagnation Ethylene Flame," Combust. Flame, Vol. 162, No. 9, Sept. 2015, pp. 3356-3369.

${ }^{18}$ Park, S. and Rogak, S., "A Novel Fixed-Sectional Model For The Formation And Growth Of Aerosol Agglomerates," J. Aerosol Sci., Vol. 35, No. 11, Nov. 2004, pp. 1385-1404.

${ }^{19}$ Richter, H., Granata, S., Green, W., and Howard, J., "Detailed Modeling Of PAH And Soot Formation In A Laminar Premixed Benzene/Oxygen/Argon Low-Pressure Flame," Proc. Comb. Inst., Vol. 30, 2005, pp. 1397-1405.

${ }^{20}$ Ciajolo, A., Tregrossi, A., Mallardo, M., Faravelli, T., and Ranzi, E., "Experimental And Kinetic Modeling Study Of Sooting Atmospheric-Pressure Cyclohexane Flame," Proc. Combust. Inst., Vol. 32, No. 1, 2009, pp. 585-591.

${ }^{21}$ Saffaripour, M., Veshkini, A., Kholghy, M., and Thomson, M. J., "Experimental Investigation And Detailed Modeling Of Soot Aggregate Formation And Size Distribution In Laminar Coflow diffusion flames of Jet A-1, a synthetic kerosene, and n-decane," Combust. Flame, Vol. 161, No. 3, March 2014, pp. 848-863.

${ }^{22}$ Stagni, A., Cuoci, A., Frassoldati, A., Faravelli, T., and Ranzi, E., "Lumping And Reduction Of Detailed Kinetic Schemes: An Effective Coupling," Ind. Eng. Chem. Res., Vol. 53, No. 22, 2014, pp. 9004-9016.

${ }^{23}$ Stagni, A., Frassoldati, A., Cuoci, A., Faravelli, T., and Ranzi, E., "Skeletal Mechanism Reduction Through SpeciesTargeted Sensitivity Analysis," Combust. Flame, Vol. 163, 2016, pp. 382-393.

${ }^{24}$ Xu, R., Wang, K., Banerjee, S., Shao, J., Parise, T., Zhu, Y., Wang, S., Movaghar, A., Lee, D. J., Zhao, R., Han, X., Gao, Y., Lu, T., Brezinsky, K., Egolfopoulos, F. N., Davidson, D. F., Hanson, R. K., Bowman, C. T., and Wang, H., "A Physics-Based Approach To Modeling Real-Fuel Combustion Chemistry - Ii. Reaction Kinetic Models Of Jet and rocket fuels," Combust. Flame, Vol. 193, July 2018, pp. 520-537.

${ }^{25}$ Yan, Y., Liu, Y., Fang, W., Liu, Y., and Li, J., "A Simplified Chemical Reaction Mechanism For Two-Component Rp-3 Kerosene Surrogate Fuel And Its Verification," Fuel, Vol. 227, 2018, pp. 127-134.

${ }^{26}$ Zettervall, N., Fureby, C., and Nilsson, E., "A Reduced Chemical Kinetic Reaction Mechanism For Kerosene-Air Combustion," Fuel, Vol. 269, June 2020, pp. 117446. 
${ }^{27}$ Eigentler, F., Gerlinger, P., Aigner, M., and Eggels, R., "Development and Application of a Reversible PAH Formation Model for Soot Prediction in Complex Fuel CFD Applications," Volume 4A: Combustion, Fuels, and Emissions, American Society of Mechanical Engineers, Sept. 2020, pp. GT2020-14692.

${ }^{28}$ Eigentler, F. and Gerlinger, P., "A detailed PAH and soot model for complex fuels in CFD applications," Submitted to Flow, Turbulence and Combustion.

${ }^{29}$ Brehm, N., Baker, S. J., and Jones, S. P., "A Three Step NOx Reduction Programme: Achievements With the Single Annular Low-NOx Combustor for the BR 700 Engine Family," Volume 2: Coal, Biomass and Alternative Fuels, Combustion and Fuels, Oil and Gas Applications, Cycle Innovations, American Society of Mechanical Engineers, jun 1997, pp. 97-GT-145.

${ }^{30}$ Smiljanovski, V. and Brehm, N., "CFD Liquid Spray Combustion Analysis of a Single Annular Gas Turbine Combustor," Volume 2: Coal, Biomass and Alternative Fuels, Combustion and Fuels, Oil and Gas Applications, Cycle Innovations, American Society of Mechanical Engineers, jun 1999, pp. 99-GT-300.

${ }^{31}$ Anand, M. S., Eggels, R., Staufer, M., Zedda, M., and Zhu, J., "An Advanced Unstructured-Grid Finite-Volume Design System for Gas Turbine Combustion Analysis," ASME 2013 Gas Turbine India Conference, American Society of Mechanical Engineers, Dec. 2013, pp. GTINDIA2013-3537.

${ }^{32}$ Jones, W. and Launder, B., "The prediction of laminarization with a two-equation model of turbulence," Int. J. Heat Mass Transf., Vol. 15, No. 2, Feb. 1972, pp. 301-314.

${ }^{33}$ Chin, J. S. and Lefebvre, A. H., "Steady-state evaporation characteristics of hydrocarbon fuel drops," AIAA J, Vol. 21, No. 10, Oct. 1983, pp. 1437-1443.

${ }^{34}$ Gosman, A. D. and loannides, E., "Aspects of Computer Simulation of Liquid-Fueled Combustors," AIAA J, Vol. 7 , No. 6, Nov. 1983, pp. 482-490.

${ }^{35}$ Lignell, D. O., Chen, J. H., and Smith, P. J., "Three-dimensional direct numerical simulation of soot formation and transport in a temporally evolving nonpremixed ethylene jet flame," Combustion and Flame, Vol. 155, No. 1-2, Oct. 2008, pp. 316-333.

${ }^{36}$ Liu, F., Guo, H., Smallwood, G., and Gülder, Ö., "Effects Of Gas And Soot Radiation On Soot Formation In A Coflow Laminar Ethylene Diffusion Flame," J. Quant. Spectrosc. Radiat. Transf., Vol. 73, 2002, pp. 409-421.

${ }^{37}$ Mauss, F., Entwicklung Eines Kinetischen Modells Der Rußbildung Mit Schneller Polymerisation, Ph.D. thesis, Dissertation, Rheinisch-Westfälische Technische Hochschule Aachen, 1997.

${ }^{38}$ Slavinskaja, N., "Skeletal Mechanism For Kerosene Combustion With PAH Production," 46th Aerospace Sciences Meeting and Exhibit (2008), Vol. 46, 46th Aerospace Sciences Meeting and Exhibit (2008), January 2008, pp. $2008-992$.

${ }^{39}$ Slavinskaya, N. and Haidn, O., "Kinetic Mechanism For Low Pressure Oxygen / Methane Ignition And Combustion," 49th Aerospace Sciences Meeting including the New Horizons Forum and Aerospace Exposition (2011), Vol. 49, 49th Aerospace Sciences Meeting including the New Horizons Forum and Aerospace Exposition (2011), January 2011, pp. 2011-94.

${ }^{40}$ Frenklach, M., Clary, D., Gardiner, W., and Stein, S., "Detailed Kinetic Modeling Of Soot Formation In Shock-Tube Pyrolysis Of Acetylene," Symp. (Int.) Comb., Vol. 20, 1985, pp. 887-901.

${ }^{41}$ Warnatz, J., Maas, U., and Dibble, R., Physical And Chemical Fundamentals, Modeling And Simulation, Experiments, Pollutant Formation, Springer Science \& Business Media, Berlin Heidelberg, 2006.

42 Abid, A., Tolmachoff, E., Phares, D., Wang, H., Liu, Y., and Laskin, A., "Size Distribution And Morphology Of Nascent Soot In Premixed Ethylene Flames With And Without Benzene Doping," Proc. Combust. Inst., Vol. 32, No. 1, 2009, pp. 681688.

${ }^{43}$ Lindstedt, P. R., "Simplified Soot Nucleation And Surface Growth Steps For Non-Premixed Flames," Springer Ser. Chem. Phys., 1994, pp. 417-441.

${ }^{44}$ Frenklach, M. and Wang, H., "Detailed Modeling Of Soot Particle Nucleation And Growth," Symp. (Int.) Comb., Vol. 23, No. 1, January 1991, pp. 1559-1566.

${ }^{45}$ Eberle, C., Ein effizienter Sektionalansatz zur Modellierung von PAHs und nicht sphärischen Rußpartikeln unter technisch relevanten Verbrennungsbedingungen, Ph.D. thesis, Universität Stuttgart, 2020.

${ }^{46}$ Di Domenico, M., Gerlinger, P., and Aigner, M., "Development and validation of a new soot formation model for gas turbine combustor simulations," Combust. Flame, Vol. 157, No. 2, Feb. 2010, pp. 246-258.

${ }^{47}$ Fenimore, C. P. and Jones, G. W., "Oxidation Of Soot By Hydroxyl Radicals," J. Phys. Chem., Vol. 71, No. 3, Feb. 1967, pp. 593-597.

${ }^{48}$ Appel, J., Bockhorn, H., and Frenklach, M., "Kinetic Modeling Of Soot Formation With Detailed Chemistry And Physics: Laminar Premixed Flames Of C2 Hydrocarbons," Combust. Flame, Vol. 121, No. 1-2, April 2000, pp. 122-136.

${ }^{49}$ Liu, F., Guo, H., Smallwood, G., and Gülder, Ö. L., "Numerical Modelling Of Soot Formation And Oxidation In Laminar Coflow Non-Smoking And Smoking Ethylene Diffusion Flames," Combust. Theory Model., Vol. 7, No. 2, June 2003 , pp. 301-315.

${ }^{50}$ Krestinin, A., "On The Mechanism Of Soot Formation From Acetylene," Chem. Phys. Reports, Vol. 13, 1994, pp. 191-210.

${ }^{51}$ Krestinin, A., "Polyyne Model Of Soot Formation Process," Symp. (Int.) Comb., Vol. 27, 1998, pp. 1557-1563.

${ }^{52}$ Krestinin, A., "Detailed Modeling Of Soot Formation In Hydrocarbon Pyrolysis," Combust. Flame, Vol. 121, 2000, pp. 513-524.

${ }^{53}$ EASA, "ICAO Aircraft Engine Emissions Databank," https : / / www . easa . europa . eu / domains / environment / icao-aircraft-engine-emissions-databank, 2021, [Online; accessed 11-May-2021]. 